\title{
Utilisation of the oceanic habitat by king penguins over the annual cycle
}

\author{
Jean-Benoît Charrassin*, Charles-André Bost \\ Centre d'Ecologie et Physiologie Energétiques, Centre National de la Recherche Scientifique, 3 rue Becquerel, \\ 67087 Strasbourg Cedex, France
}

\begin{abstract}
The distribution and behaviour of foraging seabirds depend on the physical features of the ocean at different time and space scales, but little is known for penguins. We investigated the foraging behaviour of king penguins in relation to oceanographic features over the birds' complete annual cycle. A total of 44 birds was followed between 1994 and 1997 at the Crozet Islands to monitor foraging habitat, diving behaviour, and sea temperature of the water column, using satellitetracking and time-temperature-depth recorders (TDR) carried by the birds. The study included breeding in summer, the winter period of chick raising, and the post-moult period in spring. King penguins foraged in 2 specific regions in response to the seasonal changes in local prey availability. In summer, satellite-tracked birds during the incubating and brooding stages $(\mathrm{n}=14)$ preferentially exploited the polar front located 340 to $450 \mathrm{~km}$ to the south of their breeding site. TDR-equipped birds $(\mathrm{n}=12)$ also foraged at the polar front in summer as indicated by the vertical temperature profiles. In autumn and winter, satellite tracks $(n=8)$ and sea temperature measurements of TDRequipped birds $(n=8)$ showed that birds with crèching chicks instead foraged in antarctic waters, with $70 \%$ of individuals reaching the latitude of the pack-ice limit (1600 km from the colony). This suggests better prey availability than in the polar frontal zone at that time. When the birds were at the latitude of the polar front, the thickness of the surface mixed layer (SML) ranged from $80 \mathrm{~m}$ in summer to $140 \mathrm{~m}$ in winter, the SML temperature was $\sim 4^{\circ} \mathrm{C}$ and the thermocline had a mean maximum gradient of $-0.5^{\circ} \mathrm{C}$ for each $10 \mathrm{~m}$ depth. When the birds were at their most southerly position, the depth of the SML ranged from $100 \mathrm{~m}$ in autumn to $150 \mathrm{~m}$ in winter, while its temperature ranged from -0.8 to $2^{\circ} \mathrm{C}$. The temperature gradient of the thermocline showed an inversion in autumn, and this gradient was positive in winter (mean maximum gradient of $0.3^{\circ} \mathrm{C}$ for each $10 \mathrm{~m} \mathrm{depth}$ ). Except for spring birds $(\mathrm{n}=4)$ and for 1 winter bird, where the SML exceeded the diving range, all TDRequipped penguins $(n=19)$ dived preferentially in and below the depth of the thermocline, thereby minimising diving in the SML. Therefore, their prey may have been predictably concentrated below the SML through oceanographic processes. In king penguins, the strategy of going south could then have evolved in relation to the thinning of the SML towards the south at any time of the year.
\end{abstract}

KEY WORDS: Habitat use · Foraging $\cdot$ King penguins · Diving $\cdot$ Sea temperature $\cdot$ Thermocline Predictability $\cdot$ Southern Ocean

\section{INTRODUCTION}

The foraging behaviour of seabirds largely depends on the distribution and predictability of

*Present address: Laboratoire d'Océanographie Physique, Muséum National d'Histoire Naturelle, 43 rue Cuvier, 75231 Paris Cedex 05, France. E-mail: jbc@mnhn.fr their prey. The distribution of the prey species is correlated to various degrees with the physical and biological features of the ocean. According to their foraging range and mode, at-sea distribution of seabirds is related to physical processes at different geographic and temporal scales (Hunt \& Schneider 1987, Ainley \& DeMaster 1990, Hunt et al. 1999). 
For nearshore species of the northern hemisphere such as alcids, physical processes at small geographic scales and over shallow waters (such as the interaction of bottom topography and tidal current) influence the concentration of plankton and make it available to birds near the surface (Hunt 1991). Offshore, volant species such as those inhabiting the Southern Ocean may rely on bathymetric features or on mesoscale physical features of the deep, open ocean. Evidence comes from studies on individual albatrosses, which are concentrated at edges of island shelves or at oceanic fronts at certain periods of their annual cycle (Rodhouse et al. 1996, Weimerskirch 1997). While their ability to travel at a low cost allows them to take advantage of localised prey concentrations, they appear to explore the surface ocean essentially at random, with the probability of finding prey increasing with the area covered (Weimerskirch et al. 1994).

In contrast, diving seabirds such as penguins generally travel more slowly than volant birds and travel at a much higher energy cost. In addition, prey are not visible from a distance as they are for other birds. Therefore, diving birds should rely particularly on prey showing a predictable spatial distribution (Brown 1980, Wilson \& Wilson 1990, Costa 1991, Gaston \& Jones 1998).

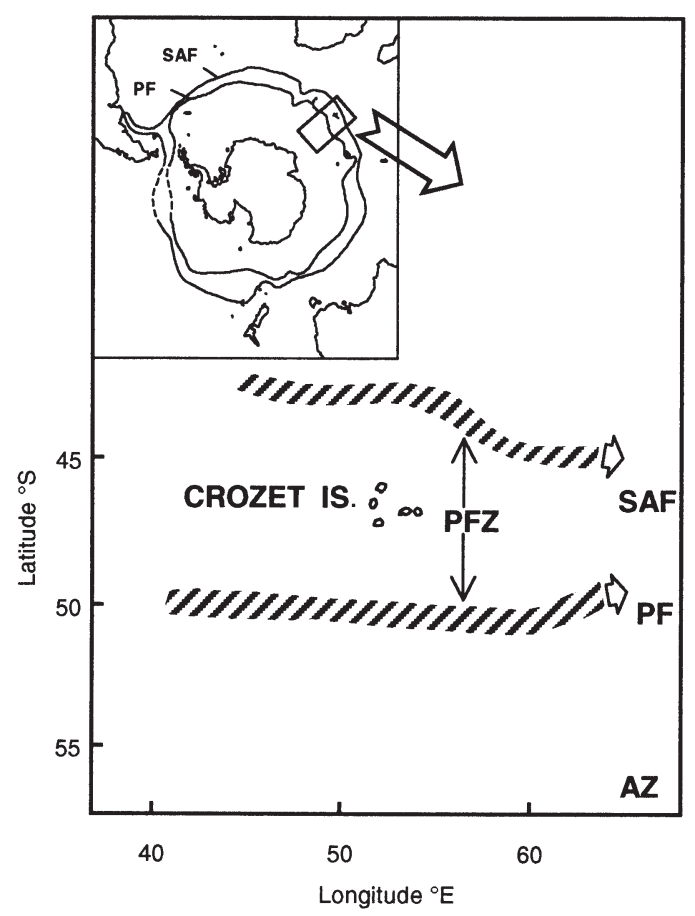

Fig. 1. Study area and major oceanographic structures of the Crozet sector. AZ: Antarctic zone; PF: Polar front; PFZ: Polar frontal zone; SAF: Sub-antarctic front. Data from Park et al. (1991, 1997), Belkin \& Gordon (1996)
Studies of the horizontal movement of some oceanic penguin species have revealed that they indeed forage preferentially at large-scale physical features such as oceanic fronts (Bost et al. 1997, Hull et al. 1997). However, although these predators spend nearly $50 \%$ of their time underwater (Charrassin et al. 1998), whether and how penguins use hydrographic features in the vertical dimension remains virtually unknown. Shipbased studies of emperor penguins have suggested that they may rely on subsurface fronts while foraging over the shelf break, but records of the diving behaviour at such sites are not available (Ainley et al. 1998). Studying the relation between individual diving behaviour of penguins and the local hydrology appears essential, therefore, for understanding how oceanographic features affect foraging patterns in terms of prey predictability. Such studies are now possible because animals can readily carry miniaturised sampling instruments that record both behavioural and environmental parameters (e.g. Wilson et al. 1994, Campagna et al. 2000, Georges et al. 2000, Koudil et al. 2000).

King penguins Aptenodytes patagonicus are exceptional among diving seabirds. They travel considerable distances at sea, commonly more than $400 \mathrm{~km}$ from the colony (Bost et al. 1997). They are also the best avian divers apart from emperor penguins A. forsteri since they frequently dive to depths $>300 \mathrm{~m}$ (Kooyman et al. 1992, Charrassin et al. 1998, Pütz et al. 1998). King penguin foraging habitat and diving behaviour have been studied extensively in summer (Kooyman et al. 1992, Jouventin et al. 1994, Bost et al. 1997, Charrassin et al. 1998, Pütz et al. 1998), but information is sparse for other seasons (Jouventin et al. 1994, Moore et al. 1999). Interestingly, the distribution of their main prey, myctophid fish, depends on the water temperature (Hulley 1981), which makes this parameter potentially important for the penguin hunting strategy. We address here 2 main questions: (1) what are the main foraging areas of king penguins throughout their annual cycle, including during the winter period of chick rearing and the post-moult stage in spring; and (2) what is the importance of the local hydrographic features, including those in the vertical dimension, for the diving patterns throughout the year?

\section{METHODS}

Study area. The study was conducted from 1994 to 1997 at 'La Grande Manchotière' colony, Possession Island, Crozet Archipelago ( $\left.46^{\circ} 25^{\prime} \mathrm{S}, 51^{\circ} 45^{\prime} \mathrm{E}\right)$, where about 40000 pairs of king penguins breed. The whole Crozet Archipelago (1 million pairs) has $~ 50 \%$ of the 
world population (Guinet et al. 1995). The Crozet Archipelago (mean annual air temperature $8^{\circ} \mathrm{C}$ ) lies in the polar frontal zone (PFZ), which is the northern boundary of the antarctic zone (Fig. 1). The PFZ is the area between the sub-antarctic front (located at $\sim 43^{\circ} \mathrm{S}$ ) and the polar front (at $\sim 50^{\circ} \mathrm{S}$ in April) (Park et al. 1993), which are major fronts of the Southern Ocean (Fig. 1). The polar front is defined by the northernmost extent of the subsurface $2{ }^{\circ} \mathrm{C}$ temperature minimum, which corresponds to a sea surface temperature (SST) of 4 to $5^{\circ} \mathrm{C}$ (Park et al. 1993, 1998). The antarctic zone lies south of the polar front down to the antarctic continent.

The distribution of the summer properties of the surface mixed layer (SML) and of the underlying layer in the study area is shown in Fig. 2. These 2 layers are separated by a vertical temperature gradient (or thermocline). In the Southern Ocean, the temperature of the SML is lowest during winter. In summer, a seasonal warming occurs in the upper part of the SML, while a part of the previous winter's mixed layer persists below (characterised by the minimum temperature attained during the previous winter). These underlying waters constitute in summer the subsurface temperature minimum and define the 'winter water' (Park et al. 1998). The SML and winter water temperatures decrease towards the south, as do the SML thickness and the winter water depth (Fig. 2).

Birds and study periods. Forty-four birds were studied and equipped so that king penguins were represented over their complete annual cycle (Fig. 3). Horizontal movements at sea were monitored in 23 birds during the 1994, 1996 and 1997 breeding seasons, and diving behaviour was monitored in 21 birds during the 1995 and 1996 breeding seasons. Brooding birds were tending a 1 to 3 wk-old chick and birds at the autumn and winter crèche stage were caring for an emancipated chick (i.e. older than $6 \mathrm{wk}$ ). Birds at the postmoult stage (spring 1996) were unsuccessful breeders from 1995.

Deployment of satellite transmitters. The movements of penguins at sea were tracked by satellite (CLS Argos, Toulouse, France). Birds were fitted with

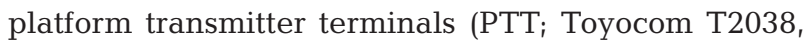
Tokyo, Japan, and Telonics ST-10, Mesa, AZ). The transmission interval was $90 \mathrm{~s}$ with either a continuous emission or an on-off interval ( 6 or $12 \mathrm{~h}$ ). The transmitters had a cylindrical form and a cross sectional area of $4.9 \mathrm{~cm}^{2}$ (ST-10 model, length $180 \mathrm{~mm}$, weight $270 \mathrm{~g}$ ) or $7.0 \mathrm{~cm}^{2}$ (T2038 model, length $224 \mathrm{~mm}$, weight $208 \mathrm{~g}$ ). At the incubating and brooding stages, birds were caught before departure to sea after having been relieved on the nest by their partner. At the crèche stages, penguins were captured after their parental link with a chick had been ascertained. In order to

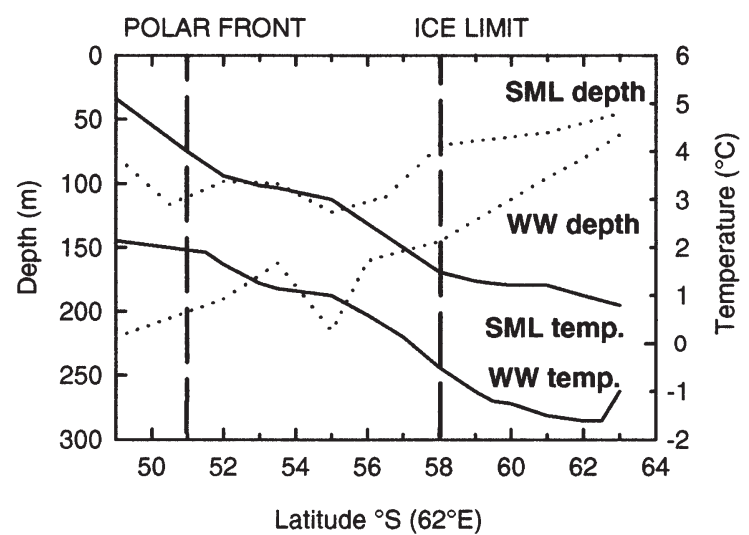

Fig. 2. Summer distribution of the surface mixed layer (SML) and winter water (WW) properties (depth and temperature) along the $62^{\circ} \mathrm{E}$ section (adapted from Fig. 5 of Park et al. 1998). The ice limit is defined as the northernmost extent of the pack-ice

reduce drag (Bannasch et al. 1994) the PTTs were hydrodynamically shaped and fitted to the lower back with the antennae posterior. The devices were attached with cable-ties to a small metal grid glued (with fast epoxy) to the feathers of the back or fixed directly to the feathers with a cyanoacrylate adhesive (Loctite 420). Birds were flipper marked with coloured tape. Care was taken to reduce handling stress (by covering birds' eyes with a dark hood). The equipping procedure took ca $40 \mathrm{~min}$. After the equipment was attached, the birds were released in the colony.

Time-temperature-depth recorder deployment and sampling procedure. Twenty-one king penguins were observed for diving behaviour and sea water temperature during 24 foraging trips using time-temperaturedepth recorders (TDRs). All foraging trips monitored were performed by different birds except for 3 birds whose foraging activity was studied at the incubating and brooding stages consecutively on the same animals (Fig. 3). Birds at the post-moult stage were randomly captured just after moult in the earliest cohort of moulting penguins. TDRs (Wildlife Computers, Redmond, WA) were fitted using the same method as for the PTTs. TDRs deployed in summer, autumn, and winter were Mk5 $3.0(95 \times 38 \times 15 \mathrm{~mm})$ and those used at the post-moult stage were Mk5 $3.3(110 \times 38 \times$ $15 \mathrm{~mm})$. The hydrodynamics of the instruments were improved by adding a small resin nose cone in the frontal position. All instruments had a 512 kbyte memory.

The MK5s logged hydrostatic pressure with $2 \mathrm{~m}$ depth resolution over a range of 0 to $500 \mathrm{~m}$ and sea water temperature to the nearest $0.1^{\circ} \mathrm{C}$. To minimise the response time of the temperature sensor, the TDRs were modified so that the temperature probe protruded slightly from the unit. The time constant was 


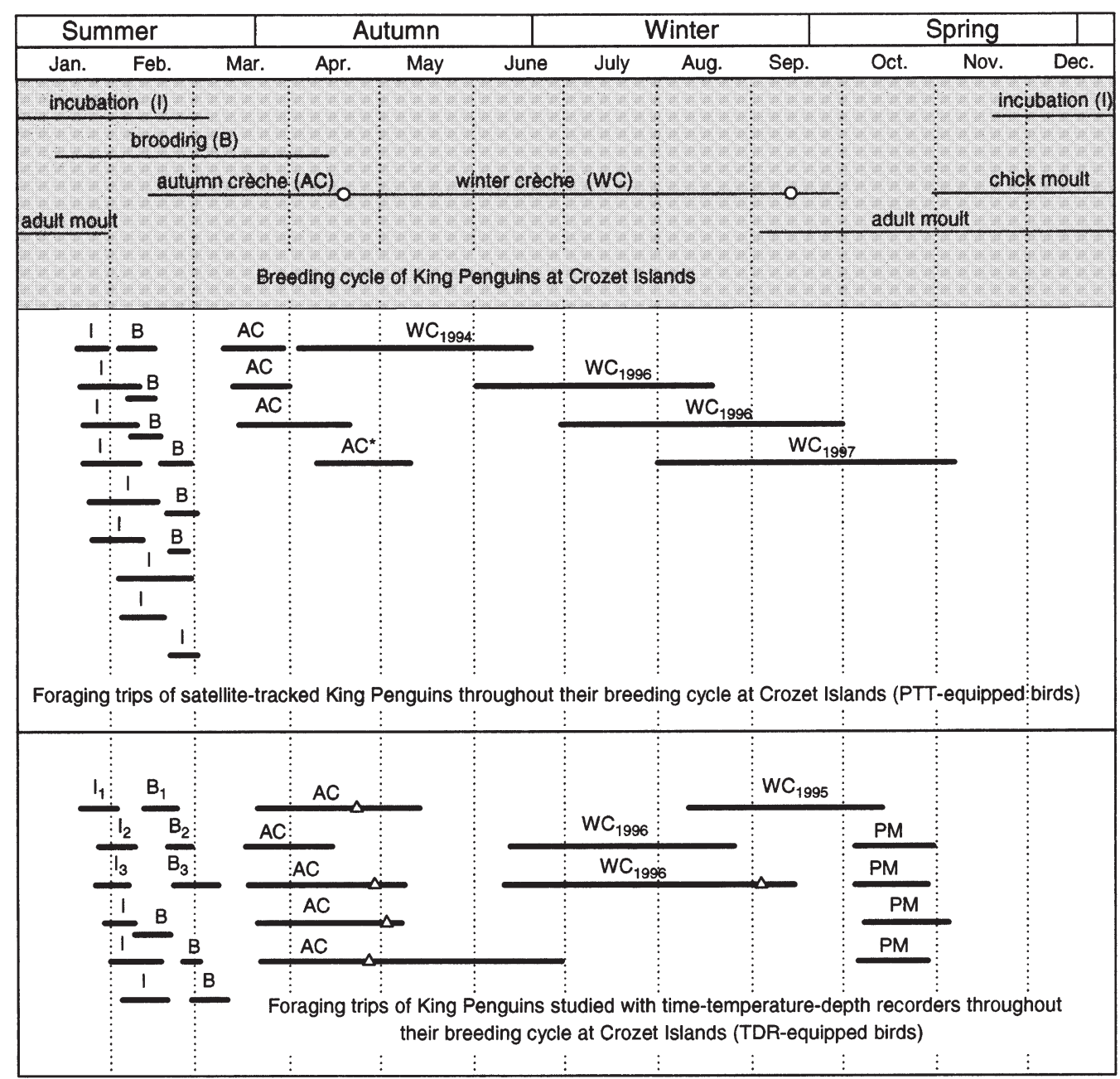

Fig. 3. Phenology of breeding in king penguins at Crozet Islands (thin horizontal lines); (o) beginning and end of the winter fast (data from Weimerskirch et al. 1992). Foraging trips of king penguins throughout the annual cycle (heavy horizontal lines), studied with platform transmitter terminals (PTTs) or time-temperature-depth recorders (TDRs). Each trip corresponds to a single individual except for the incubating and brooding trips showing the same subscript $(1,2,3)$ that were studied consecutively on the same animal, with each subscript corresponding to one individual. For PTT-equipped birds, incubating and brooding, autumn crèche, and winter crèche stages were studied in 1994-96, 1994, and 1994-96-97, respectively. One autumn crèche bird (*) was not followed over the complete trip because of an early failure of PTT batteries and was not seen again at the colony. For TDRequipped birds, incubating and brooding stages were studied in 1995; trips at other stages were recorded in 1996 except for 1 winter crèche bird obtained in 1995. PM: post-moult stage of adults. Sampling started when birds entered the water. $(\Delta)$ End of sampling by TDR (memory full) if it occurred before the bird returned to the colony

$6 \mathrm{~s}$, and when a TDR was moved between 2 water baths at different temperatures, $95 \%$ of the total temperature change was attained in less than $20 \mathrm{~s}$. King penguins have a maximum vertical velocity of $1.5 \mathrm{~m} \mathrm{~s}^{-1}$ (Pütz et al. 1998) and may thus travel $\sim 30 \mathrm{~m}$ vertically in $20 \mathrm{~s}$. In the study area the maximum vertical temperature gradient is $\sim 0.04^{\circ} \mathrm{C} \mathrm{m}^{-1}$ (Park et al. 1998), corresponding to a $1.2^{\circ} \mathrm{C}$ change over $30 \mathrm{~m}$. Thus, at depths with strong temperature gradients, a maximum difference of $1.2^{\circ} \mathrm{C}$ is expected between recorded and 'real' values. This deviation may not be uniform during descent and ascent phases of the dives, but should be biassed to an over-estimation of the actual temperature during the descent phase of the dives and an underestimation during the ascent phase. As our vertical temperature profiles have been calculated by averaging temperatures from both ascent and descent phases of the dives, we believe that much of the errors induced by the response time of our probes were essentially cancelled out.

Depth was recorded every $5 \mathrm{~s}$ in summer and every 10 s during autumn, winter, and post-moulting periods to allow for complete coverage of long trips. For the same reason, depth and sea water temperature were measured every second day in the winter crèche group. Sea water temperature was recorded every 
20 to $60 \mathrm{~s}$ when depth was $>40 \mathrm{~m}$, with the sampling maintained for $40 \mathrm{~s}$ during ascent above $40 \mathrm{~m}$ to record the SST. In the following analysis, we take SST as the mean water temperature from 0 to $10 \mathrm{~m}$.

Analysis of foraging zones (PTT-equipped birds). Locational data were processed and analysed with customised software. Locations with 7 classes of accuracy are provided by the Argos system (Argos 1996). The classes 0, A, B, and Z were filtered following Wienecke \& Robertson (1997). The travelling speed at a given position was determined by averaging the speeds found between 2 consecutive positions over a period including the 2 previous and the 2 next locations of this given position. We rejected data giving an average swimming speed higher than $14 \mathrm{~km} \mathrm{~h}^{-1}$ since this value has been found to be the mean maximum swimming velocity for king penguin (Kooyman \& Davis 1987). When data were incomplete due to battery failure, the total distance covered included the direct-line distance from the last point only if the bird was engaged in the return journey. Results from birds tracked during summer 1994 (Bost et al. 1997) have been included in this study. Contemporaneous, monthly data on SST were obtained from the Lamont-Doherty Earth Observatory at Columbia University (USA) and the Integrated Global Ocean Service System (IGOSS). The extension of the pack-ice was obtained from monthly ERS data (CERSAT, IFREMER, France).

Analysis of diving behaviour in relation to water temperature at depth (TDR-equipped birds). Using custom-made software (Jensen Software Systems, Laboe, Germany), depth data were corrected for the drift in the surface measurements. Only dives $\geq 4 \mathrm{~m}$ were analysed because dives $<4 \mathrm{~m}$ were considered unresolvable by the TDR. Dives and SST were studied daily. We examined the diving behaviour in relation to the thermal structure of the water column by plotting the depth-temperature profiles during the different phases of the foraging trips. Two days of the central and transit phases of the trips were chosen for this purpose, during which temperature values were averaged for every $10 \mathrm{~m}$ depth interval and the frequency distributions of dive depth (10 m depth interval) were obtained. These periods were choosen as follows: (1) Central phase: We studied all groups during the $2 \mathrm{~d}$ when SST was the coldest, i.e. when birds were at the most southerly position of their trip. (2) Transit phase: We studied the autumn crèche, winter crèche, and post-moult groups during the 6th and 7th day after departure, i.e. during a period comparable with the central phase of birds foraging during summer (incubating and brooding stages) by being at similar distances from the colony ( 6 to 7 foraging days) but that occurred well before the most southerly position of the trips was reached.
Foraging range of TDR-equipped birds. The foraging latitudes of TDR-equipped penguins during the transit and the central phases of the trips were inferred from the temperature-depth profiles recorded for the birds. For this, based on the known distribution of the water layer properties (Park et al. 1998 and Fig. 2), winter water temperature recorded from the penguins in spring, summer, and autumn (or extrapolation of the SML temperature in winter) were extrapolated to give the approximate foraging latitudes of the birds. Data were also compared with the corresponding weekly SST maps from IGOSS. For all of the study, means are given $\pm \mathrm{SE}$.

Effect of instruments on foraging behaviour. The effect of instruments on foraging was examined by comparing the trip durations of our equipped penguins with those of device-free conspecifics. Trip durations of TDR-equipped $(10.7 \pm 1.3 \mathrm{~d}, \mathrm{n}=6)$ and PTT-equipped $(10.0 \pm 0.7 \mathrm{~d}, \mathrm{n}=6)$ birds at the brooding stage were similar $(\mathrm{U}=14, \mathrm{p}>0.05)$. Trip durations of both TDRand PTT-equipped brooding birds were longer than those of control birds $(6.8 \pm 0.7 \mathrm{~d}, \mathrm{n}=8)(\mathrm{U}=7$ vs TDRequipped birds, $\mathrm{p}=0.031$, and $\mathrm{U}=5$ vs PTT-equipped birds, $p=0.015)$. At the winter crèche stage, trip durations of both TDR-equipped (78.0 $\pm 9.5 \mathrm{~d}, \mathrm{n}=3)$ and PTT-equipped birds $(86.8 \pm 5.4 \mathrm{~d}, \mathrm{n}=4)$ were also longer than for control birds $(50.1 \pm 7.7 \mathrm{~d}, \mathrm{n}=10)$ (Mann-Whitney $U=10, \mathrm{p}=0.017$ when TDR- and PTTequipped birds were pooled to be compared with the control group). However, because we compared instrumented birds at several stages of the annual cycle, differences found among groups in our study were mostly due to the stage of the annual cycle rather than to the instrumentation itself.

\section{RESULTS}

\section{Seasonal changes in foraging areas (PTT-equipped birds)}

Summer (incubating and brooding stages)

The foraging areas varied substantially according to season. During summer (January to mid-March), king penguins exploited mostly the PFZ, covering a total area of $265815 \mathrm{~km}^{2}$. Generally the trips were oriented towards the antarctic polar front, although 1 bird foraged to the northeast, i.e. towards the subantarctic front (Fig. 4a). During incubation, mean maximum foraging ranges were generally greater than during the brooding period $(U=7, p<0.05$, Table 1), with birds of both groups reaching the polar front area $\left(48.3^{\circ}\right.$ to $\left.50.3^{\circ} \mathrm{S}\right)$ before going back to the colony. 
Table 1. Characteristics of the tracks of foraging platform transmitter terminal (PTT) -equipped king penguins at Crozet Islands for the different breeding stages. The maximum foraging distances among groups differed significantly $\left(H_{3}=17.1, \mathrm{p}<0.001\right.$, Kruskall-Wallis test). See also Fig. 3

\begin{tabular}{|c|c|c|c|c|}
\hline \multirow[t]{2}{*}{ Breeding stage } & \multirow[t]{2}{*}{ Bird } & \multirow[t]{2}{*}{ Locations received (n) } & \multicolumn{2}{|c|}{ Maximum foraging range } \\
\hline & & & Coordinates $\left({ }^{\circ}\right)$ & Distance $(\mathrm{km})$ \\
\hline \multirow[t]{3}{*}{ Incubating (PTT, 1994) } & $315-1^{\mathrm{a}}$ & 21 & $50.52 \mathrm{~S}-52.18 \mathrm{E}$ & 456 \\
\hline & $238-2^{\mathrm{a}}$ & 29 & $49.15 \mathrm{~S}-52.26 \mathrm{E}$ & 304 \\
\hline & $239-1^{a}$ & 49 & $50.07 \mathrm{~S}-51.81 \mathrm{E}$ & 405 \\
\hline \multirow[t]{7}{*}{ Incubating (PTT, 1996) } & $570-1$ & 20 & $48.51 \mathrm{~S}-56.44 \mathrm{E}$ & 415 \\
\hline & $597-1$ & 53 & $50.02 \mathrm{~S}-52.38 \mathrm{E}$ & 402 \\
\hline & $598-1$ & 115 & $52.31 \mathrm{~S}-52.29 \mathrm{E}$ & 655 \\
\hline & $599-1$ & 69 & $50.64 \mathrm{~S}-55.78 \mathrm{E}$ & 550 \\
\hline & $600-1$ & 63 & $52.19 \mathrm{~S}-52.68 \mathrm{E}$ & 644 \\
\hline & $890-1$ & 25 & $51.35 \mathrm{~S}-53.40 \mathrm{E}$ & 560 \\
\hline & Mean $\pm \mathrm{SE}$ & $49 \pm 10$ & & $448 \pm 40$ \\
\hline \multirow[t]{7}{*}{ Brooding (PTT, 1994) } & 238-1 & 47 & $49.77 \mathrm{~S}-54.74 \mathrm{E}$ & 428 \\
\hline & $240-1$ & 37 & $49.21 \mathrm{~S}-51.35 \mathrm{E}$ & 318 \\
\hline & $240-2$ & 38 & $49.91 \mathrm{~S}-52.30 \mathrm{E}$ & 397 \\
\hline & $316-1$ & 19 & $45.72 \mathrm{~S}-55.43 \mathrm{E}$ & 295 \\
\hline & $316-2$ & 24 & $49.30 \mathrm{~S}-53.60 \mathrm{E}$ & 356 \\
\hline & $317-2^{\mathrm{b}}$ & 9 & $48.47 \mathrm{~S}-51.18 \mathrm{E}$ & 236 \\
\hline & Mean \pm SE & $29 \pm 6$ & & $338 \pm 29$ \\
\hline \multirow[t]{5}{*}{ Autumn crèche (PTT, 1994) } & $238-3$ & 66 & $49.89 \mathrm{~S}-58.15 \mathrm{E}$ & 605 \\
\hline & $316-3$ & 33 & $53.42 \mathrm{~S}-55.23 \mathrm{E}$ & 815 \\
\hline & $317-3$ & 39 & $57.27 \mathrm{~S}-58.11 \mathrm{E}$ & 1279 \\
\hline & $239-3^{\mathrm{b}}$ & 148 & $59.44 \mathrm{~S}-59.41 \mathrm{E}$ & 1532 \\
\hline & Mean $\pm \mathrm{SE}$ & $46 \pm 10$ & & $900 \pm 199$ \\
\hline \multirow[t]{5}{*}{ Winter crèche (PTT, 1994-96-97) } & $316-4$ & 119 & $60.67 \mathrm{~S}-47.65 \mathrm{E}$ & 1608 \\
\hline & $598-2$ & 34 & $62.13 \mathrm{~S}-42.01 \mathrm{E}$ & 1856 \\
\hline & $315 \mathrm{H}$ & 154 & $59.50 \mathrm{~S}-45.93 \mathrm{E}$ & 1475 \\
\hline & $570 \mathrm{H}$ & 53 & $59.76 \mathrm{~S}-55.17 \mathrm{E}$ & 1495 \\
\hline & Mean $\pm \mathrm{SE}$ & $90 \pm 28$ & & $1609 \pm 88$ \\
\hline
\end{tabular}
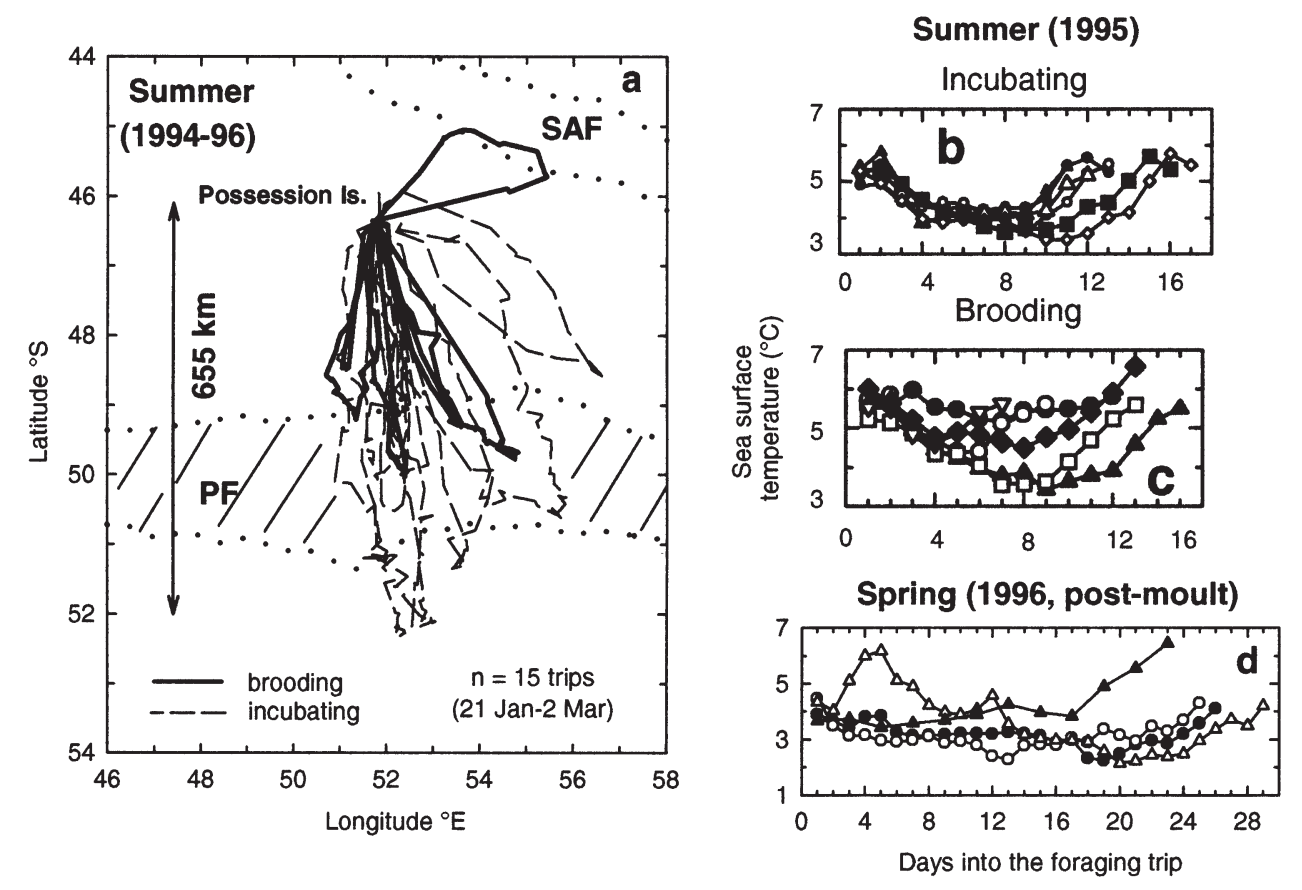

Fig. 4. (a) Tracks of PTTequipped king penguins from Possession Island (Crozet Archipelago) during summer (incubating and brooding stages). The mean position of the PF and the SAF (Park et al. 1993) during the study period were obtained from Integrated Global Ocean Service System (IGOSS) data. Daily changes in sea surface temperature for TDR-equipped king penguins during the (b) incubating and (c) brooding stages, and (d) at the post-moult stage (spring). Within each group, each symbol pertains to 1 individual 


\section{Autumn crèche}

From mid-March, the maximum foraging range and distance covered increased dramatically, in agreement with the prolonged absences from the colony (Fig. 5a, Table 1). In April, the birds continued to head southeast, up to $1532 \mathrm{~km}$ from the colony, and stopped in waters with SST between 3 and $1{ }^{\circ} \mathrm{C}$ (Fig. 5a).

\section{Winter crèche}

During winter, the distances covered and the foraging ranges were the highest, the total area encompassed $\left(1128205 \mathrm{~km}^{2}\right.$ ) being up to 4 times the area used in summer, even though the number of birds sam-

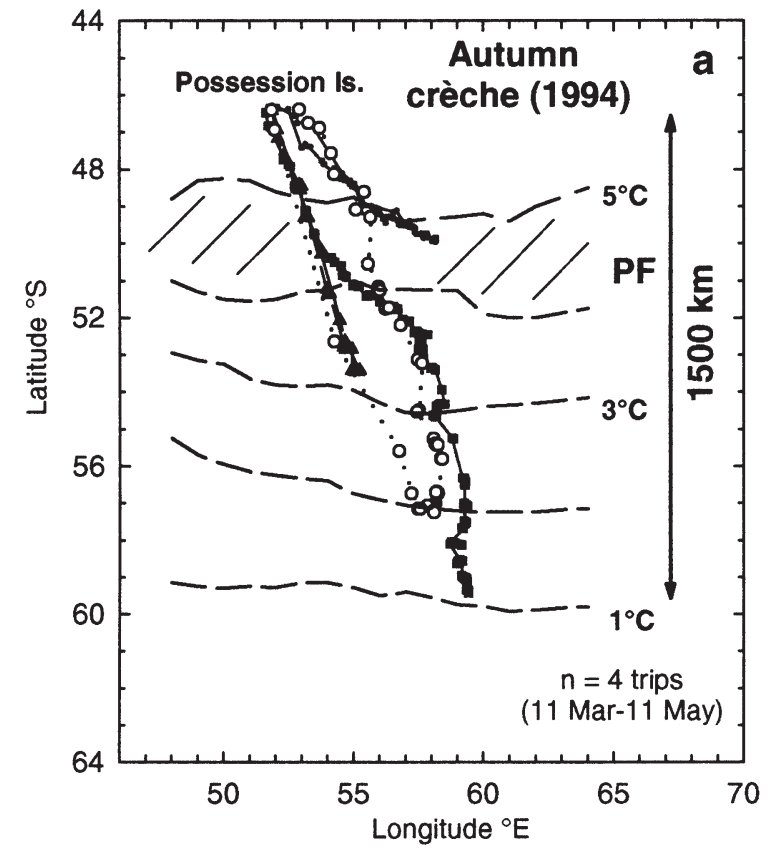

Autumn crèche (1996)

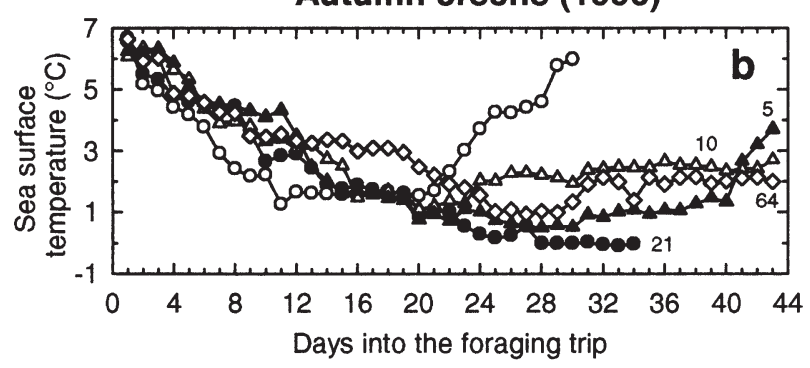

Fig. 5. (a) Tracks of PTT-equipped king penguins from Crozet Islands at the autumn crèche stage (mean sea surface isotherms corresponding to April 1994; IGOSS data). (b) Daily changes in sea surface temperature for TDR-equipped king penguins during the autumn crèche stage. The number of days before return is indicated on the SST curves if sampling stopped before the end of the trip pled was smaller. After departure, the birds headed directly south, crossing the northern limit of the light pack-ice (56 to $62^{\circ} \mathrm{S}$, Fig. 6a). After crossing this limit, the birds stayed in this zone for between 14 and $43 \mathrm{~d}$ (mean $18 \pm 9 \mathrm{~d}, \mathrm{n}=4$ ) before traveling directly back to the colony.

\section{Hydrographic features of the foraging habitat (TDR-equipped birds)}

\section{Changes in daily SST during the foraging trips}

The mean SST encountered by birds typically decreased to a minimum on the outward phase of the trip before rising gradually to near initial values as the
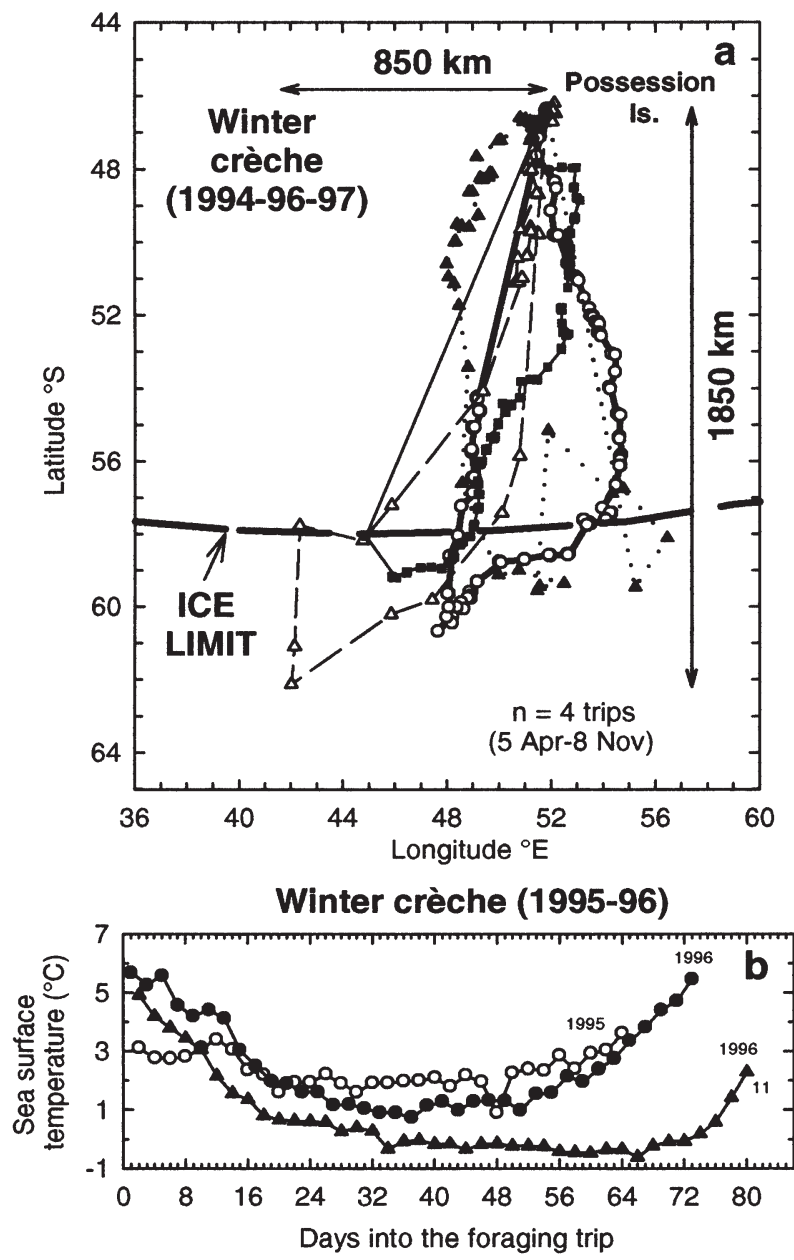

Fig. 6. (a) Tracks of PTT-equipped king penguins from Crozet Islands during the winter crèche stage with the mean limit of the pack-ice (ice density index 1 to 3 ) in August 1994-96-97 (CERSAT data, IFREMER). (b) Daily changes in sea surface temperature for TDR-equipped king penguins at the winter crèche stage 
(a) Summer (central) Incubation (I) Brooding (I)

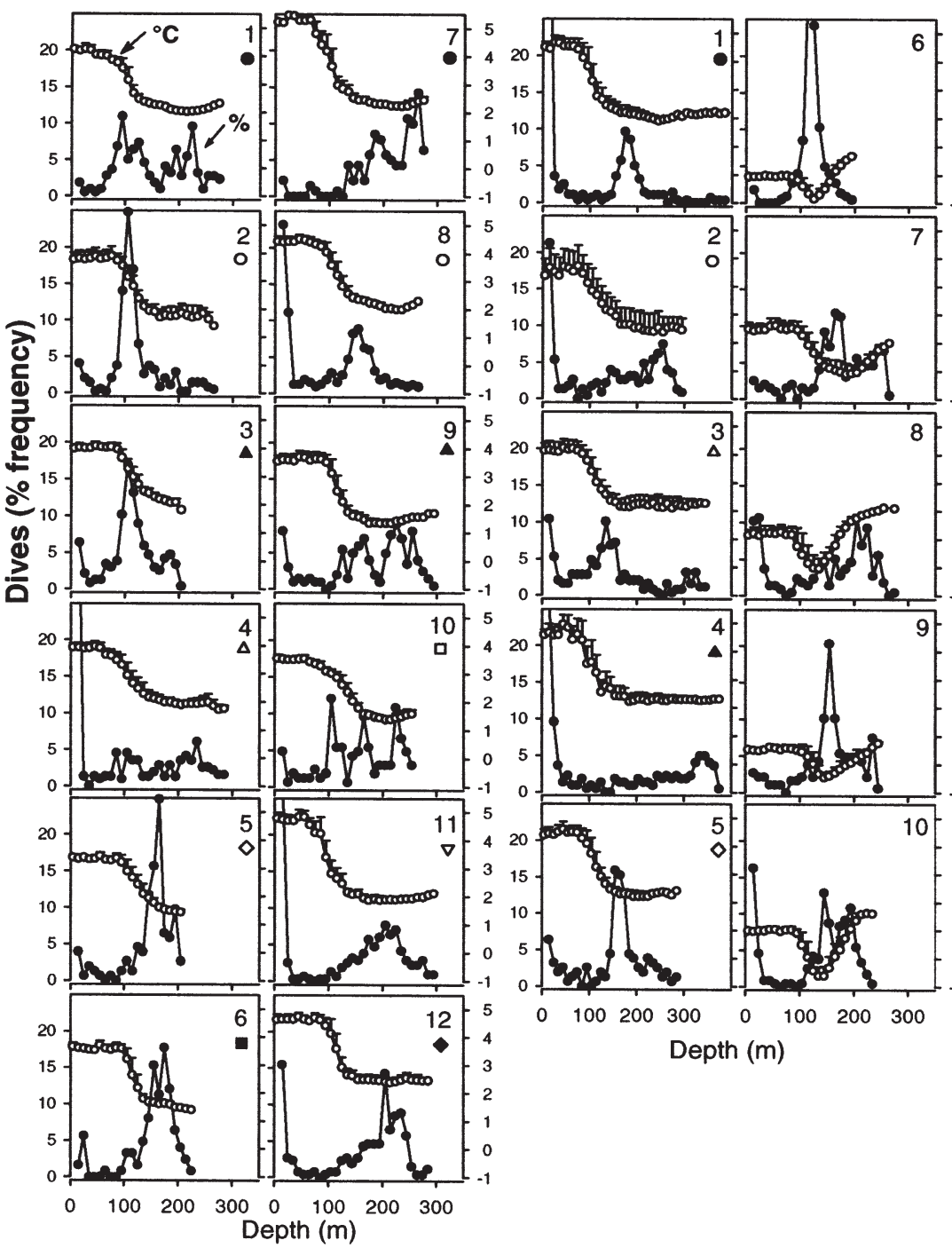

Fig. 7. Dive frequencies (dives $>10 \mathrm{~m}$ ) for every $10 \mathrm{~m}$ depth interval as a percentage (closed symbols) and sea water temperature (open symbols) as a function of depth, calculated during the central phase ( $2 \mathrm{~d}$ of coldest sea surface temperature) for TDR-equipped king penguins during the incubating, brooding, autumn crèche, winter crèche, and post-moult stages ( $\mathrm{a} 1$ to $\mathrm{a} 6, \mathrm{a} 7$ to $\mathrm{a} 12$, b6 to b10, $\mathrm{c} 4$ to $\mathrm{c} 6$ and $\mathrm{d} 5$ to d8, respectively), and during the transit phase (Days 6 to 7 of the trip) for the autumn crèche, winter crèche, and post-moult stages (b1 to b5, c1 to $c 3$, and d1 to $\mathrm{d} 4$, respectively); Roman numerals indicate the type of thermal profile as defined in 'Results' (except for $\star$ that were Type V profiles). Temperature values were dataaveraged for every $10 \mathrm{~m}$ depth interval. Within each group, the data pertains to the individuals of Figs 4 to 6 with the same symbol as indicated in the upper right-hand portion of each box; the summer graphs refer to data derived from 9 birds; the autumn, winter, and spring graphs refer to data derived from 5, 3, and 4 birds, respectively, with, for each individual, a graph for the transit phase and a graph for the central phase (c) Winter (crèche)

Transit (II) Central (IV)

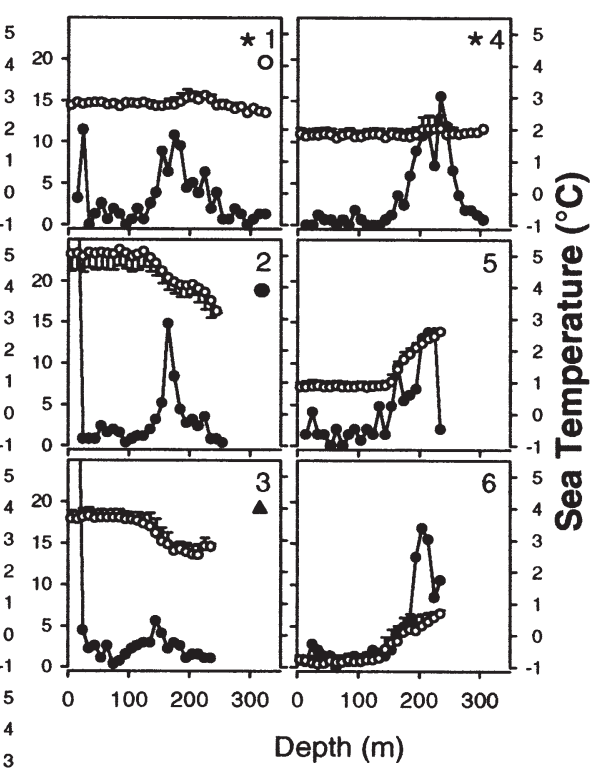

(d) Spring (post-moult)

Transit (V) Central (V)

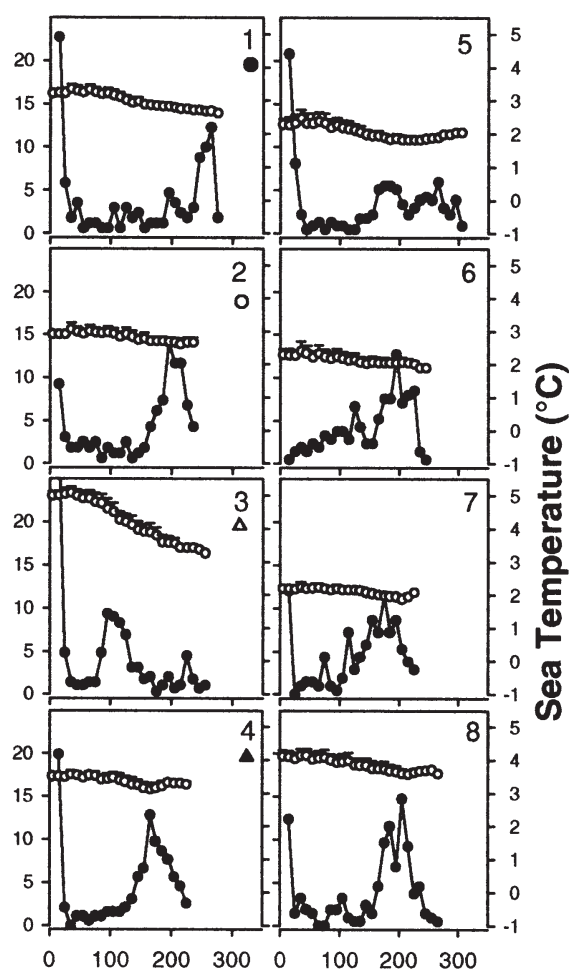

Depth (m) birds returned (Figs $4 b-d, 5 b$ \& 6b). Average mean SSTs at departure were $5.2,5.6,6.4,4.6$, and $4.1^{\circ} \mathrm{C}$ for incubating, brooding, autumn crèche, winter crèche, and post-moult groups, respectively, reflecting the sea- sonal changes in SST at Crozet Islands. Averages of the minimum SSTs of the trips were lower during the autumn and winter trips $\left(0.7\right.$ and $0.6^{\circ} \mathrm{C}$, respectively) than during the spring and summer trips $(2.5,3.8$, and 
$4.3^{\circ} \mathrm{C}$ in post-moulting, incubating, and brooding birds, respectively).

Vertical temperature profiles

Five types of thermal profiles were identified from sea temperature data obtained with TDR-equipped penguins: (1) Type I, rapid temperature decline (Fig. 7a,b1 to b5): For incubating and brooding birds during the central phase, and for autumn birds during the transit phase, temperature profiles were characterised by an SML thickness of $80 \mathrm{~m}$ on average (range 60 to $100 \mathrm{~m}$ ) with a temperature of 3.5 to $5^{\circ} \mathrm{C}$, followed by a rapid decline to $\sim 2^{\circ} \mathrm{C}$ at 130 to $230 \mathrm{~m}$ (average of maximum temperature gradients $-0.5^{\circ} \mathrm{C}$ every $10 \mathrm{~m}$ ) where temperature leveled out. (2) Type II, low temperature decline (Fig. 7c2,c3): This was found during the transit phase of winter birds, and resembles Type I, although the SML was thicker $(\sim 140 \mathrm{~m})$ and the temperature drop below the SML was less abrupt (maximum temperature gradients $-0.3^{\circ} \mathrm{C}$ every $10 \mathrm{~m}$ ). (3) Type III, temperature inversion (Fig. $7 \mathrm{~b} 6$ to b10) and (4) Type IV, temperature rise (Fig. 7c5,c6): For autumn and winter crèche birds during the central phase, the SML was cold $\left(-0.8\right.$ to $\left.1.8^{\circ} \mathrm{C}\right)$ and had an average thickness of $100 \mathrm{~m}$ in autumn and $145 \mathrm{~m}$ in winter. Temperatures then either dropped (with a mean maximum temperature of $-0.35^{\circ} \mathrm{C}$ every $10 \mathrm{~m}$ ) to an average of $0.3^{\circ} \mathrm{C}$ (range -0.9 to $0^{\circ} \mathrm{C}$ ) before rising (with a mean maximum temperature gradient of $0.35^{\circ} \mathrm{C}$ every $10 \mathrm{~m}$ ) to 1 to $2^{\circ} \mathrm{C}$ at 200 to $300 \mathrm{~m}$ in autumn (Type III) or increased directly to 1 to $2^{\circ} \mathrm{C}$ at 200 to $300 \mathrm{~m}$ in winter (with a maximum temperature gradient of $0.35^{\circ} \mathrm{C}$ every $10 \mathrm{~m}$ ) (Type IV). For 1 winter bird (Fig. $7 \mathrm{c} 1, \mathrm{c} 4)$, however, the thermal profiles ressembled Type $\mathrm{V}$ (see below) with a temperature of $2^{\circ} \mathrm{C}$ during the central phase. (5) Type V (deep SML) (Fig. 7d): For birds at the post-moult stage, the SML reached 250 to $300 \mathrm{~m}$. The SML temperatures were $\sim 3.5^{\circ} \mathrm{C}$ and 2.2 to $2.5^{\circ} \mathrm{C}$ for the transit and the central phases, respectively, except for 1 bird that encountered an SML at $4{ }^{\circ} \mathrm{C}$ during the central period of its trip (Fig. 7d8).

Seasonal changes in foraging areas inferred from thermal profiles

The Type I thermal profile found in incubating and brooding birds (central phase) and during the transit phase of autumn crèche birds corresponds to the polar front area with an SST of 4 to $5^{\circ} \mathrm{C}$ and a subsurface temperature minimum of $2^{\circ} \mathrm{C}$ at $200 \mathrm{~m}$ (Fig. 2). This is in good agreement with the foraging areas of satellite-tracked birds at the same breeding stages.

Subsurface minima (winter water) ranging from -0.9 to $0^{\circ} \mathrm{C}$ in autumn and SML temperatures ranging from -0.8 to $1.8^{\circ} \mathrm{C}$ in winter indicate that TDR-equipped birds foraged at latitudes ranging from 57 to $59^{\circ} \mathrm{S}$ and from 52 to $59^{\circ} \mathrm{S}$ in autumn and winter, respectively (Fig. 2). All autumn TDR-equipped birds reached latitudes where the pack-ice was apparently in formation (winter SML having not yet been established; Type III). In winter, 1 bird reached the pack-ice limit (Type IV, Fig. $7 \mathrm{c} 6$ ). If PTT-equipped birds are included, 7 out of 9 birds reached the ice limit region in autumn (before ice formation) and 5 out of 7 foraged at the pack-ice limit in winter. In spring, the Type V profile was typical of the area north of 50 to $51^{\circ} \mathrm{S}$ (Fig. 2). The birds' positions obtained in this way were also confirmed by contemporaneous SST satellite maps.

\section{Diving behaviour in relation to thermal profiles (TDR-equipped birds)}

If traveling dives $(\leq 20 \mathrm{~m})$ are excluded, the frequency distribution of dive depths for most of the birds was clearly skewed towards depths greater than 70 m (Fig. 7). Dive depths (averages of individual mean dive depths for dives $>70 \mathrm{~m}$ ) were greatest during the transit phase in autumn crèche birds $(204 \pm 18 \mathrm{~m})$ and during the central phase of winter crèche birds $(204 \pm 16 \mathrm{~m})$. They were shallowest during the central phase of incubating (161 \pm $13 \mathrm{~m}$ ) and autumn crèche birds $(167 \pm 12 \mathrm{~m})$, and were intermediate during the central phase of brooding birds $(192 \pm 9 \mathrm{~m})$ and during the transit $(177 \pm 16 \mathrm{~m})$ and central $(183 \pm 11 \mathrm{~m})$ phases of post-moulting birds.

Comparison of the frequency distribution of dive depths with the thermal profile recorded simultaneously indicates that in most cases birds avoided diving in the part of the water column corresponding to the SML (Fig. 7). Instead, they dived either in parts of the water column characterised by large temperature gradients (thermocline depths) or in the underlying deep layer. During incubation, 3 birds out of 6 dived mainly in the thermocline (Fig. 7a2,a4 \& a5). At the brood stage, the birds mainly dived at the base of the thermocline (Fig. 7a8,a10) or in the deep layer. This was also observed during the transit phase in autumn (Fig. $7 \mathrm{~b} 1$ to b5) and for winter crèche birds (Fig. 7c2,c3). During the central part of their trips, autumn birds typically dived at the depth of the temperature inversion below the SML (Fig. $7 \mathrm{~b} 6$ to b10), and winter birds dived in the deep positive thermocline (Fig. 7c5,c6). At the post-moult stage in spring, the temperature was homogeneous in the water column and preferred diving depths were generally greater than $150 \mathrm{~m}$. 


\section{DISCUSSION}

Ours is the first study to examine the 3-dimensional exploitation of the water mass in relation to hydrographic features by diving seabirds throughout their complete annual cycle. King penguins did not forage randomly, but utilised specific oceanic areas and adjusted their foraging activity to the water mass explored.

\section{Foraging at the polar front in summer}

The present work has elucidated the extent of the foraging habitat of king penguins, with the importance of the polar front being well confirmed. Most of the PTT- and all of the TDR-equipped birds headed south towards the polar front, where they ended their outward trip, with the trips ranging on average 340 and $450 \mathrm{~km}$ at the brooding and incubating stages, respectively (PTT-equipped birds). The same daily decreases of SST recorded after a bird's departure to minimum values of $\sim 4^{\circ} \mathrm{C}$ typical of the polar front (TDR-equipped birds) were also obtained from remote-sensed SST data interpolated from tracks of satellite-tracked king penguins (Guinet et al. 1997). The importance of the polar front for king penguins was first suggested by Jouventin et al. (1994), being strongly backed by data of Bost et al. (1997), Guinet et al. (1997), and Pütz et al. (1998) in telemetric studies. The consistency of this pattern over several years of study shows that the PFZ is the main summer foraging habitat of king penguins of the South Indian Ocean. Interestingly, those king penguins breeding south of the polar front (South Georgia and Heard Island) forage north of their colony in the area of the polar front (Rodhouse et al. 1998, Moore et al. 1999), as did sympatric volant predators, grey-headed albatrosses (Diomedea chrystoma, Rodhouse et al. 1996). In the southern Pacific Ocean, royal penguins Eudyptes schlegeli were also dependent on the polar front located south of the Macquarie Islands in summer (Hull et al. 1997). It appears, therefore, that this oceanic structure is a key foraging area for predators able to travel large distances during breeding. It is known that frontal areas are privileged places of biological activity due to mechanical concentration of phytoplankton or increased in situ production through enhanced availability of nutrients (Franks 1992, Laubscher et al. 1993, Pakhomov et al. 1994). Consequently, abundance of zooplankton secondary consumers is enhanced (Pakhomov et al. 1994), which in turn results in locally increased seabird densities (Pakhomov \& McQuaid 1996, Rodhouse et al. 1996).

\section{Foraging at the ice-edge area in autumn and winter}

In autumn and winter king penguins undertook nonrandom migrations towards areas located as far south as the pack-ice region. All PTT-equipped birds headed south in trips characterised by ranges increasing substantially from autumn to winter. Similar foraging habitats were used by TDR-equipped birds, as inferred from the SST typically decreasing after their departure and by the characteristic thermal profiles at their most southerly positions. Most birds $(77 \%)$ studied with both types of equipment reached the ice limit region in autumn (before ice formation) and foraged at the packice limit in winter $(71 \%)$. In terms of foraging range, our data agree well with those found in autumn and in early winter and winter at Crozet Islands (Jouventin et al. 1994) and at Heard Island (Moore et al. 1999). The light pack-ice area is thus a major foraging ground in winter for the king penguin populations of the Indian Ocean sector of the Southern Ocean. Among other penguins, such distant trips from the colony $(>1000 \mathrm{~km})$ compare only with those of juvenile emperor penguins Aptenodytes forsteri (Kooyman et al. 1996) and Adélie penguins Pygoscelis adeliae during their non-breeding winter migrations (Davis et al. 1996). Utilisation of antarctic waters in autumn and winter by king penguins strongly suggests a drastic drop in prey availability in the PFZ at the end of March. Despite reduced trophic activity of pelagic ecosystems in winter, the ice edge's physical features increase biological production. Primary production is greater at the ice edge than within the pack-ice because of a higher light level. The water column at the ice edge is also probably more stable vertically than in open waters, which favours primary production (Knox 1994). Through zooplankton, this enhanced biological activity may make the ice edge an attractive spot for top predators (Hopkins et al. 1993). Consistent with this idea, high densities of marine birds and mammals have been observed at the ice edge in winter (Ainley et al. 1991, Ribic et al. 1991).

\section{Diving behaviour and vertical temperature profiles}

We show that the diving behaviour of king penguins depends strongly on the hydrothermal structure of the water column, with penguins avoiding the SML during most of their annual cycle.

In summer, depth-temperature profiles observed for incubating and brooding birds have shown that king penguins dived substantially in and below the thermal discontinuity separating the SML and the underlying waters. This strategy may be related to the physical properties of the water strata explored. In diving 
predators, such preference for thermocline depths has been described only in southern elephant seals (Boyd \& Arnbom 1991). Thermal gradients in oceans are generally accompanied by salinity and density gradients (Park et al. 1998). Discontinuities in physical properties of the water column may result in enhanced biological activity because of the 'barrier effect' of the density gradients leading to a concentration of sinking matter (Boyd \& Arnbom 1991). These nutrient-rich water layers may attract prey such as mesopelagic myctophid fish. The 2 main prey of king penguins from the Crozet Islands during summer are the myctophids Electrona carlsbergi and Krefftichthys anderssoni (Cherel \& Ridoux 1992, Bost et al. 1997), which are opportunistic mesozooplankton consumers (Pakhomov et al. 1996). Despite the important role of myctophids in pelagic ecosystems (Sabourenkov 1991), detailed information on their vertical distribution is lacking (Duhamel 1998). Our penguin dive data may indicate that a substantial part of myctophids were distributed in and below the thermocline, perhaps due to interactions with their prey. In addition, the temperature in the lower part of the thermocline is close to the thermal optimum for myctophids $\left(2.6\right.$ to $\left.5^{\circ} \mathrm{C}\right)$ consumed in summer by king penguins (Hulley 1981).

In autumn, king penguins dived deeper in the polar front area (transit phase) than in summer, suggesting that prey were less accessible in the PFZ. It is known that the summer prey of king penguins (e.g. Electrona carlsbergi) migrate to great depths at the end of the summer, probably to follow their own zooplankton prey, which overwinter in deep waters (Kozlov et al. 1991). Presumably as a response to this drop in prey availability in the PFZ, king penguins continued towards the south. At their southernmost position (57 to $59^{\circ} \mathrm{S}$ ), they consistently dived in waters with typical strong temperature inversions at relatively shallow depths ( 130 m, Fig. $7 \mathrm{~b} 6$ to b10). If prey actually concentrate at water column discontinuities, birds may be able to exploit the thermocline at shallower depths by heading south. Indeed, at any time of the year, the SML thickness decreases at higher latitudes (Fig. 2).

In winter, king penguins foraged deep and consistently in the thermocline all along their foraging trip. The SML reaches its greatest extent in winter (corresponding to the winter water depth, Fig. 2). Since there is a good correlation between the thermocline depths and penguins' diving behaviour, the lower depths of prey in winter may have been partly related to the descending thermocline in winter. Because long trip durations result in complete digestion that prevents prey identification (Cherel et al. 1993, 1996), there is little information on prey eaten in the pack-ice area by king penguins. The myctophid Electrona antarctica may be an important part of their winter diet, since it is the main myctophid species in the marginal sea-ice zone and an important winter prey of seabirds in this region (Ainley et al. 1991, Lancraft et al. 1991). Our dive data show a productive depth strata at 200 to $250 \mathrm{~m}$, to which most dives were directed, and which may be indicative of the daily winter vertical distribution of E. antarctica in this region. Overall, for penguins foraging in winter, and as suggested for autumn birds, prey may be located at shallower depths in antarctic waters than in the PFZ due to the decrease of SML thickness towards the south. Therefore, at any time of the year, penguins tend to find prey at shallower depths by heading south rather than by staying at lower latitudes.

In spring, king penguins used a rather different foraging strategy from that in other seasons. The foraging ranges of TDR-equipped birds inferred from SST and thermal profiles indicate that they did not go further south than the latitudes where the polar front lies in summer. Prey were thus abundant enough to prevent trips to remote antarctic areas as in autumn and winter. This pattern agrees with the only data available to date taken from the Crozet Islands (Jouventin et al. 1994), showing that king penguins made south-eastward trips in spring that did not take them farther south than in the summer. At Heard Island, king penguins foraging in spring also showed foraging ranges that appeared less than in summer (Moore et al. 1999). In spring, king penguins resumed intense feeding on the same myctophid species as before winter (Cherel et al. 1993, Raclot et al. 1998), but little is known of the spring distribution of myctophids. The data suggest that they reenter the penguins' diving range in the PFZ, probably through a general upward migration to track the seasonal upward migration of zooplankton (Kozlov et al. 1991). In comparison with autumn and winter, changes in the hydrothermal structure encountered by the birds over their trip in spring were small, probably due to the reduced latitudinal displacements of the birds at this time. In addition, the thick SML provided a constant water temperature over the whole penguin diving range, without gradients that favour prey concentration (Franks 1992, Laubscher et al. 1993). Therefore, in spring birds foraged without apparent hydrographic cues for prey that were probably more randomly distributed than in other seasons.

In conclusion, our study shows that for birds travelling by swimming in the marine environment, hydrographic features on both short and large scales are important components of the foraging strategy. By diving king penguins can take advantage of the thermal discontinuities below the SML. As long-distance foragers, they exploit remote, but predictable, areas of the ocean (polar front, ice edge) according to seasonal changes in local prey availability. Such long trips may 
be efficient because penguins can continuously use the thermal gradients found at depth thanks to their deep diving ability. For king penguins, the strategy of heading south when prey availability decreases in the PFZ may have evolved in relation to the thinning of the SML towards the south. Such strategy allows them to exploit mesopelagic resources all year round. Whether king penguins either directly use thermal gradients at depth as cues to find prey or feed opportunistically on prey predictably concentrated through hydrographic process is a fascinating topic for future research.

Acknowledgements. This work is a part of a long-term research project on penguin ecophysiology (no. 137) directed by Y. Le Maho, to whom we are indebted for constant help and support. The Institut Français pour la Recherche et la Technologie Polaire and the Terres Australes et Antarctiques Françaises provided financial and logistical support. The Centre National de la Recherche Scientifique and GDRE 1069 also helped fund this work. The Penguin Fund (Tokyo, Japan) has kindly provided J.B.C. with a grant. We thank E. Valentini, Y. Ropert-Coudert, Y. Clerquin, and N. Lambert for collection of data in the field, and S. Eudes, G. Froget, and M. Gauthier-Clerc for fieldwork assistance. We also thank the staffs of the 31st to 34th Missions at Crozet Islands. The Lamont-Doherty Observatory at Colombia University (USA) and the IGOSS provided sea surface temperature data. R. Ezraty kindly provided CERSAT (IFREMER, France) sea-ice data. T. Zorn and G. Wittersheim offered abundant statistical advice. J. Lage and Y. Handrich aided extensively by writing customised software for data analysis. We are also indebted to Y.$\mathrm{H}$. Park for helpful discussions on hydrology of the Southern Ocean, and M. Fukuchi and K. Kawaguchi for highlights in plankton and prey biology. Finally, we are particularly grateful to Y. Cherel and R. Wilson for their helpful comments on the manuscript.

\section{LITERATURE CITED}

Ainley DG, DeMaster DP (1990) The upper trophic levels in polar marine ecosystems. In: Smith WO Jr (ed) Polar oceanography, Part B: chemistry, biology, and geology. Academic Press, San Diego, p 599-630

Ainley DG, Fraser WR, Smith WO Jr, Hopkins TL, Torres JJ (1991) The structure of upper level pelagic food webs in the Antarctic: effect of phytoplankton distribution. J Mar Syst 2:111-122

Ainley DG, Jacobs SS, Ribic CA, Gaffney I (1998) Seabird distribution and oceanic features of the Amundsen and southern Bellingshausen seas. Antarct Sci 10:111-123

Argos (1996) Argos User Manual. Argos CLS, Toulouse, France

Bannasch R, Wilson RP, Culik B (1994) Hydrodynamic aspects of design and attachment of a back-mounted device in penguins. J Exp Biol 194:83-96

Belkin IM, Gordon AL (1996) Southern ocean front from the Greenwich meridian to Tasmania. J Geophys Res 101: 3675-3696

Bost CA, Georges JY, Guinet C, Cherel Y and 6 others (1997) Foraging habitat and food intake of satellite-tracked king penguins during the austral summer at Crozet Archipelago. Mar Ecol Prog Ser 150:21-33

Boyd IL, Arnbom T (1991) Diving behaviour in relation to water temperature in the southern elephant seal: foraging implications. Polar Biol 11:259-266

Brown RGB (1980) Seabirds as marine animals. In: Burger J, Olla BL, Winn HE (eds) Behavior of marine animals, 4 (marine birds). Plenum Press, New York, p 1-39

Campagna C, Rivas AL, Marin MR (2000) Temperature and depth profiles recorded during dives of elephant seals reflect distinct ocean environments. J Mar Syst 24:299-312

Charrassin JB, Bost CA, Pütz K, Lage J and 3 others (1998) Foraging strategies of incubating and brooding king penguins Aptenodytes patagonicus. Oecologia 114:194-201

Cherel Y, Ridoux V (1992) Prey species and nutritive value of food fed during summer to king penguin Aptenodytes patagonica chicks at Possession Island, Crozet Archipelago. Ibis 134:118-127

Cherel Y, Verdon C, Ridoux V (1993) Seasonal importance of oceanic myctophids in king penguin diet at Crozet Islands. Polar Biol 13:355-357

Cherel Y, Ridoux V, Rodhouse PG (1996) Fish and squid in the diet of king penguin chicks, Aptenodytes patagonicus, during winter at sub-antarctic Crozet Islands. Mar Biol 126:559-570

Costa DP (1991) Reproductive and foraging energetics of high latitude penguins, albatrosses and pinnipeds: implications for life history patterns. Am Zool 31:111-130

Davis LS, Boersma PD, Court GS (1996) Satellite telemetry of the winter migration of Adélie penguins (Pygoscelis adeliae). Polar Biol 16:221-225

Duhamel G (1998) The pelagic fish community of the polar frontal zone off the Kerguelen Islands. In: di Prisco G, Pisano E, Clarke E (eds) Fishes of Antarctica. A biological overview. Springer-Verlag Italia, Milano, p 63-74

Franks PJS (1992) Phytoplankton blooms at fronts: patterns, scales, and physical forcing mechanisms. Rev Aquat Sci 6: 121-137

Gaston AJ, Jones IL (1998) The auks. Oxford University Press, New York

Georges JY, Bonadonna F, Guinet C (2000) Foraging habitat and diving activity of lactating subantarctic fur seals in relation to sea-surface temperatures at Amsterdam Island. Mar Ecol Prog Ser 196:291-304

Guinet C, Jouventin P, Malacamp J (1995) Satellite remote sensing in monitoring change of seabirds: use of spot image in king penguin population increase at Ile aux Cochons, Crozet Archipelago. Polar Biol 15:511-515

Guinet C, Koudil M, Bost CA, Durbec JP and 3 others (1997) Foraging behaviour of satellite-tracked king penguins in relation to sea-surface temperatures obtained by satellite telemetry at Crozet Archipelago, a study during three austral summers. Mar Ecol Prog Ser 150:11-20

Hopkins TL, Lancraft TM, Torres JJ, Donnelly J (1993) Community structure and trophic ecology of zooplancton in the Scotia Sea marginal ice zone in winter (1988). Deep-Sea Res I 40:81-105

Hull CL, Hindell MA, Michael K (1997) Foraging zones of Royal penguins during the breeding season, and their association with oceanographic features. Mar Ecol Prog Ser 153:217-228

Hulley PA (1981) Results of the research cruise of FRV 'Walter Herwig' to South America. LVIII family Myctophidae (Osteicthyes, Myctophiformes). Archiv Fischereiwiss 42:1-300

Hunt GL Jr (1991) Marine ecology of seabirds in polar oceans. Am Zool 31:131-142

Hunt GL Jr, Schneider DC (1987) Scale-dependent processes in the physical and biological environment of marine birds. In: Croxall JP (ed) Seabirds: feeding ecology and 
role in marine ecosystems. Cambridge University Press, Cambridge, p 9-41

Hunt GL, Mehlum F, Russell RW, Jones D, Decker MB, Becker PH (1999) Physical processes, prey abundance, and the foraging ecology of seabirds. In: Adams NJ, Slotow RH (eds) Proceedings of the 22nd International Ornithological Congress, Durban. BirdLife South Africa, Johannesburg, p 2040-2056

Jouventin P, Capdeville D, Cuenot-Chaillet F, Boiteau C (1994) Exploitation of pelagic resources by a non-flying seabird-satellite tracking of the king penguin throughout the breeding cycle. Mar Ecol Prog Ser 106:11-19

Knox GA (1994) The biology of the Southern Ocean. Cambridge University Press, Cambridge

Kooyman GL, Davis RW (1987) Diving behavior and performance, with special reference to penguins. In: Croxall JP (ed) Seabirds: feeding ecology and role in marine ecosystems. Cambridge University Press, Cambridge, p 63-75

Kooyman GL, Cherel Y, Le Maho Y, Croxall JP, Thorson PH, Ridoux V, Kooyman CA (1992) Diving behavior and energetics during foraging cycles in king penguins. Ecol Monogr 62:143-163

Kooyman GL, Kooyman TG, Horning M, Kooyman CA (1996) Penguin dispersal after fledging. Nature 383:397

Koudil M, Charrassin JB, Le Maho Y, Bost CA (2000) Seabirds as monitors of upper-ocean thermal structure: king penguins at the Antarctic polar front, east of Kerguelen sector. C R Acad Sci (Ser. 3) (Sci Vie/Life Sci) 323: 377-384

Kozlov AN, Shust KV, Zemsky AV (1991) Seasonal and interannual variability in the distribution of Electrona carlsbergi in the southern polar front area. Selected Scientific Papers Committee Conservation Antarctic Marine Living Resources (CCAMLR) 1990, Hobart, p 320-337

Lancraft TM, Hopkins TL, Torres JJ, Donnelly J (1991) Oceanic micronektonic/macrozooplanktonic community structure and feeding in ice covered antarctic waters during the winter (AMERIEZ 1988). Polar Biol 11:157-167

Laubscher RK, Perissinotto R, McQuaid CD (1993) Phytoplankton production and biomass at frontal zones in the Atlantic sector of the Southern Ocean. Polar Biol 13: $471-481$

Moore GJ, Wienecke B, Robertson G (1999) Seasonal change in foraging area and dive depths of breeding king penguins at Heard Island. Polar Biol 21:376-384

Pakhomov EA, McQuaid CD (1996) Distribution of surface zooplankton and seabirds across the Southern Ocean. Polar Biol 16:271-286

Pakhomov EA, Perissinotto R, McQuaid CD (1994) Comparative structure of the macrozooplankton micronekton communities of the subtropical and antarctic polar fronts. Mar Ecol Prog Ser 111:155-169

Pakhomov EA, Perissinotto R, McQuaid CD (1996) Prey composition and daily rations of myctophid fishes in the Southern Ocean. Mar Ecol Prog Ser 134:1-14

Editorial responsibility: Otto Kinne (Editor), Oldendorf/Luhe, Germany
Park YH, Gambéroni L (1997) Cross-frontal exchange of antarctic intermediate water and antarctic bottom water in the Crozet Basin. Deep Sea Res II 44:963-986

Park YH, Gambéroni L, Charriaud E (1991) Frontal structure and transport of the antarctic circumpolar current in the South Indian Ocean sector, 40-80E. Mar Chem 35:45-62

Park YH, Gambéroni L, Charriaud E (1993) Frontal structure, water masses, and circulation in the Crozet Basin. J Geophys Res 98:12361-12385

Park YH, Charriaud E, Fieux M (1998) Thermohaline structure of the antarctic surface water/winter water in the Indian sector of the Southern Ocean. J Mar Syst 17:5-23

Pütz K, Wilson RP, Charrassin JB, Raclot T and 5 others (1998) Foraging strategy of king penguins (Aptenodytes patagonicus) during summer at the Crozet Islands. Ecology 79: 1905-1921

Raclot T, Groscolas R, Cherel Y (1998) Fatty acid evidence for the importance of myctophid fishes in the diet of king penguins, Aptenodytes patagonicus. Mar Biol 132:523-533

Ribic CA, Ainley DG, Fraser WR (1991) Habitat selection by marine mammals in the marginal ice zone. Antarct Sci 3: 181-186

Rodhouse PG, Prince PA, Trathan PN, Hatfield EMC and 4 others (1996) Cephalopods and mesoscale oceanography at the antarctic polar front: satellite tracked predators locate pelagic trophic interactions. Mar Ecol Prog Ser 136:37-50

Rodhouse PG, Olsson O, Ankernilssen P, Murray AWA (1998) Cephalopod predation by the king penguin Aptenodytes patagonicus from South Georgia. Mar Ecol Prog Ser 168: 13-19

Sabourenkov EN (1991) Myctophids in the diet of antarctic predators. Selected Scientific Papers Committee Conservation Antarctic Marine Living Resources (CCAMLR) 1990, Hobart, p 335-357

Weimerskirch H (1997) Foraging strategies of Indian Ocean albatrosses and their relationships with fisheries. In: Robertson G, Gales R (eds) Albatross biology and conservation. Surrey Beatty and Sons, Norton, p 168-179

Weimerskirch H, Stahl JC, Jouventin P (1992) The breeding biology and population dynamics of king penguins Aptenodytes patagonica on the Crozet Islands. Ibis 134: $107-117$

Weimerskirch H, Doncaster CP, Cuenot-Chaillet F (1994) Pelagic seabirds and the marine environment: foraging patterns of wandering albatrosses in relation to prey availability and distribution. Proc R Soc Lond B 255:91-97

Wienecke BC, Robertson G (1997) Foraging space of emperor penguins Aptenodytes forsteri in antarctic shelf waters in winter. Mar Ecol Prog Ser 159:249-263

Wilson RP, Wilson MPT (1990) Foraging ecology of breeding spheniscus penguins. In: Davis LS, Darby JT (eds) Penguin biology. Academic Press, San Diego, p 181-206

Wilson RP, Culik BM, Bannasch R, Lage J (1994) Monitoring antarctic environmental variables using penguins. Mar Ecol Prog Ser 106:199-202

Submitted: December 20, 2000; Accepted: March 27, 2001 Proofs received from author(s): October 5, 2001 